\title{
Synthesis and kinetics of tributyl citrate using aluminum dihydrogen tripolyphosphate supported on modified activated carbon as catalyst
}

\author{
Aiqun Yuan*, Hui Liang, Zengwei Huang, Dongping Wei \\ School of Chemistry and Chemical Engineering, Guangxi University for Nationalities, Guangxi Key \\ Laboratory of Chemistry and Engineering of Forest Products, Nanning 530006 China \\ *Corresponding author, e-mail: aiqunyuan1999@sina.com \\ Received 10 Nov 2020 \\ Accepted 9 Jan 2021
}

\begin{abstract}
The mechanism of synthesis process of tributyl citrate using aluminum dihydrogen tripolyphosphate supported on modified activated carbon as a catalyst was investigated by gas chromatography-mass spectrometry, and the kinetic equation was also studied. The results showed that the influence of internal diffusions was eliminated with the particle size smaller than $180 \mu \mathrm{m}$, but the influence of external diffusions was eliminated with the stirring speed higher than $450 \mathrm{r} / \mathrm{min}$. The yield of $97 \%$ for tributyl citrate was achieved under the the following optimized condition: 1:4.2 of acid to alcohol, $8 \%$ of dosage of catalyst accounting for total reaction amount, $5 \mathrm{~h}$ of reaction time for water segregating and refluxing, and $150{ }^{\circ} \mathrm{C}$ of reaction temperature. The apparent reaction activation energy was $E_{a}=61.4 \mathrm{KJ} / \mathrm{mol}$. The mechanism of this catalytic reaction was considered to be attributable to the fact that the steps of the esterification of citrate to produce both monobutyl citrate and dibutyl citrate were very fast, but the rate of the formation of tributyl citrate was slow. The control step of total reaction was the reaction between dibutyl citrate and n-butanol to produce tributyl citrate.
\end{abstract}

KEYWORDS: aluminum dihydrogen tripolyphosphate, modified activated carbon, tributyl citrate, kinetics, catalyze

\section{INTRODUCTION}

As a kind of both environmentally-friendly and nontoxic plasticizer, tributyl citrate (TBC) has been widely used in polyvinyl chloride (PVC), cellulose, and chlorinated olefin copolymer resin production because of its excellent properties such as compatibility, plasticizing efficiency, volatility, small size, hardiness, resistance to light, and good biodegradability [1-3] as well as it being especially suitable for food packaging, medical appliances, children's toys, and other plastic production. Usually tributyl citrate is synthesized by catalysis of concentrated sulfuric acid. Although the catalytic effect of sulfuric acid is efficient and the cost of catalyst is low, there are still some disadvantages. For example, some of these disadvantages include equipment corrosion, deep product color, by-product, complex post-processing of product, serious pollution of acidic waste-water, and so on. Many research studies have been made to look for a highly-efficient and environmentallyfriendly catalyst for the synthesis of tributyl citrate. So far, the catalytic synthesis of TBC using inorganic salt, cation exchange resin, solid superacid, and heteropoly acid has been reported. As reported, previous studies revealed that these catalysts have the advantages of high catalytic activity, stability, light color of product, and little pollution $[4,5]$. However, some disadvantages can still be observed in these developed catalysts. Unfortunately, recycling of inorganic salt catalyst is very difficult, and the cost of separation is high. Worse still, the price of ionic liquid, solid superacids, and heteropoly acid is relatively high, and the recovery for catalysts is usually complicated and expensive. The abovementioned defects hinder their applications in the production of tributyl citrate. Therefore, highperformance and low-cost catalyst for the synthesis of tributyl citrate is highly desired.

Aluminum dihydrogen tripolyphosphate dihydrate $\left(\mathrm{AlH}_{2} \mathrm{P}_{3} \mathrm{O}_{10} \cdot 2 \mathrm{H}_{2} \mathrm{O}\right.$, abbreviated as ATP $)$ is known to be a useful anti-corrosive pigment. Importantly, ATP is very environmentally-friendly. Since this environmental material has a layered structure, intercalation studies for ATP have been reported [6-8]. These studies showed that ATP can be used as the catalyst in organic reactions as a kind of solid acid proposing high Lewis acid degree and weak acid strength $[9,10]$. As a photocatalyst or a photo-induced activated material, the photocat- 
alytic activity of ATP has also been reported [11]. ATP has attracted much attention within the last 20 years; however, to the best of our knowledge, there are few reports on using ATP as catalysts for organic synthesis. We have used ATP as a catalyst instead of concentrated sulfuric acid for the synthesis of TBC. Our previous exploratory experiment found that ATP used in the synthesis of TBC has easier separation, simpler post-process, and more environmentally-friendly compared to concentrated sulfuric acid. Importantly, this synthetic process has no oxidation of organic products, no residue, no corrosion of equipment, and no pollutant emission to the environment. Credited to these factors, it is of great economic value and practical significance to investigate the catalytic process of ATP for the synthesis of TBC. However, due to small specific surface area of the product, the esterification rate of tributyl citrate ester in the catalytic synthesis is low $(<80 \%)$. Previous studies showed that the surface area of ATP could be enlarged by SDiatomite supporting, and then the catalytic activity of the ATP was improved during catalyzation of the the organic reaction. Furthermore, 90\% yield of the product was achieved $[12,13]$. However, the process of preparation includes the subliming of sulfur, which leads to environmental pollution associated with gaseous sulfur emission. In addition, some studies found the catalytic effect of TBC would be quickly improved over oxidation-treated activated carbon (AC) as a support $[14,15]$. The as-synthesized ATP catalysts loaded on activated carbon oxidation-treated with $\mathrm{Na}_{2} \mathrm{~S}_{2} \mathrm{O}_{8}$ have been reported in our previous work $[16,17]$. We found the esterification rate of tributyl citrate catalyzed by ATP/AC was $97.01 \%$, which was higher than that of other catalysts. Therefore, this new catalyst has a great application prospect in TBC synthesis. In order to accelerate the application of the catalyst research, it is necessary to study the process mechanism of TBC synthesis using ATP/AC as a catalyst. This article is a continuation of the previous investigation on ATP/AC catalyst, which also deals with the yield of TBC over the ATP/AC catalyst as well as kinetics of this catalytic reaction. Herein, this study is to provide a theoretical basis for the application development of this new heterogeneous catalyst in the future.

\section{EXPERIMENTS}

\section{Materials}

All the chemical regents in this work were used as received without further purification.

\section{Catalytic synthesis of TBC}

For preparation of ATP/AC catalyst, see [16]. nButanol and citric acid with metered proportion were taken into $250 \mathrm{ml}$ flasks fitted with a water segregator and reflux device. Acid value was determined after the citric acid was dissolved. Then, the ATP/AC catalyst was combined and stirred to heat until the end of reaction. Acid value was determined again after cooling and filtration. After adding a solution of $1 \mathrm{~mol} / 1 \mathrm{BaCl}_{2}$, filtration, washing, and decompression distillation to recover n-butanol, the product was dried with anhydrous magnesium sulfate, allowing TBC to be obtained. The esterification yield $(\alpha)$ of TBC was calculated by the acid value before $\left(x_{1}\right)$ and after the reaction $\left(x_{2}\right)$,

$$
\alpha=\frac{x_{1}-x_{2}}{x_{1}} \times 100 \% .
$$

The composition of the product was determined by gas chromatography-mass spectrometry at different reaction times (Agilent 7890A-5975C). The other experimental conditions are above the optimized conditions. Chromatographic column conditions: HP-5 type quartz capillary chromatographic column $(30.0 \mathrm{~m} \times 0.25 \mathrm{~mm} \times 0.25 \mu \mathrm{m})$. The column temperature using temperature programmed: $60^{\circ} \mathrm{C}$ for $5 \mathrm{~min}$ with $10^{\circ} \mathrm{C} / \mathrm{min}$ up to $150^{\circ} \mathrm{C}, 150^{\circ} \mathrm{C}$ for 2 min with $25^{\circ} \mathrm{C} / \mathrm{min}$ up to $280^{\circ} \mathrm{C}$, and $280^{\circ} \mathrm{C}$ for $5 \mathrm{~min}$. The injection mode is undivided injection, and the temperature of the injection port is $250^{\circ} \mathrm{C}$, the sample volume $1.0 \mu \mathrm{l}$. The carrier gas was He, and the flow rate was $1.0 \mathrm{ml} / \mathrm{min}$. The retention time of TBC was about $16.585 \mathrm{~min}$ under the above gas chromatography conditions. An infrared spectrum of the product was measured by potassium bromide pressure plate method. Refractive index of the product was also measured.

\section{RESULTS AND DISCUSSION}

\section{Effect of the influencing factors on esterification yield}

\section{Effect of internal and external diffusions}

The influence of both internal and external diffusions was investigated by changing the particle size and stirring speed of the catalyst. When the ratio of acid to alcohol was 1:4 and the added amount of ATP/AC catalyst was $8 \%$, the effects of the 2 factors on the yield of tributyl citrate under different reaction times were investigated, by changing particle size of the catalyst or stirring speed as shown in Fig. 1 or Fig. 2. It can be observed that the yield 


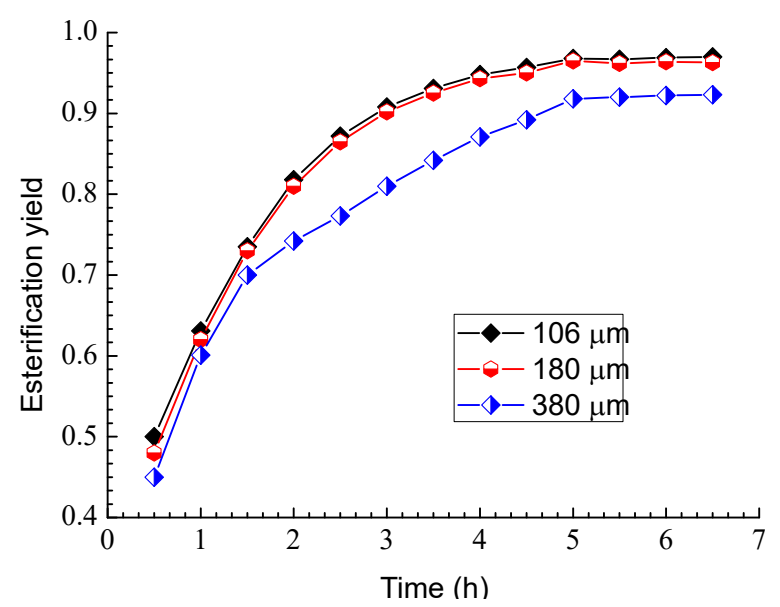

Fig. 1 Effect of particle size on esterification yield.

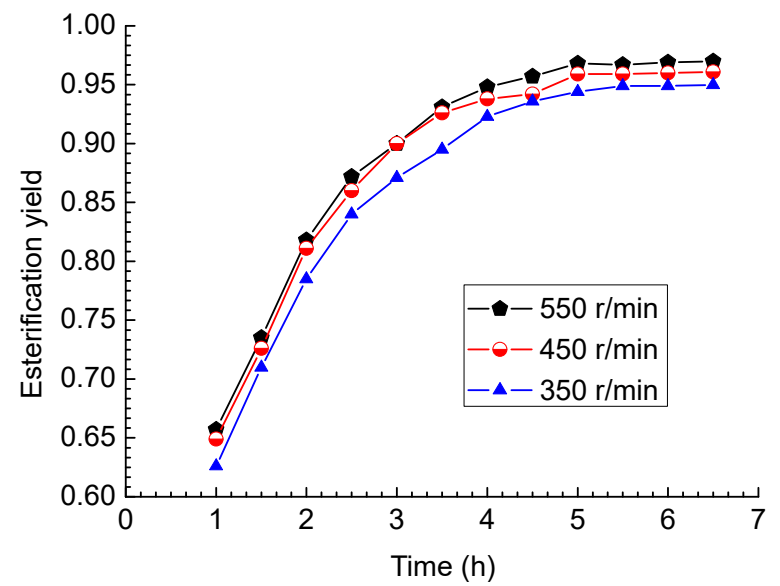

Fig. 2 Effect of stirring speed on esterification yield.

of esterification reaction was relatively lower when the particle size of catalyst was larger or the stirring speed was lower. When the particle size was smaller than $180 \mu \mathrm{m}$ and the stirring speed was higher than $450 \mathrm{r} / \mathrm{min}$, both the particle size and the stirring speed had little effect on the yield of esterification reaction. The influence of internal and external diffusions could be eliminated under this condition.

\section{Effect of reaction temperature}

When the particle size of ATP/AC catalyst was $180 \mu \mathrm{m}$, the rotational speed was $450 \mathrm{r} / \mathrm{min}$, the ratio of acid to alcohol was 1:4, and the added amount of catalyst was $8 \%$, the effect of the reaction temperature on the esterification yield under different reaction times was investigated. As shown in Fig. 3, it can be found that as the temperature increased, the reaction rate also increased. The rate would

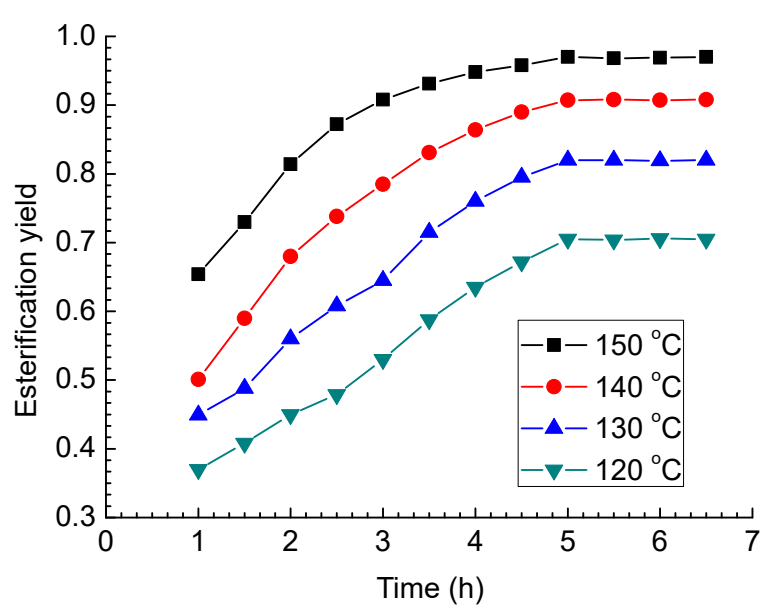

Fig. 3 Effect of reaction temperature on esterification yield.

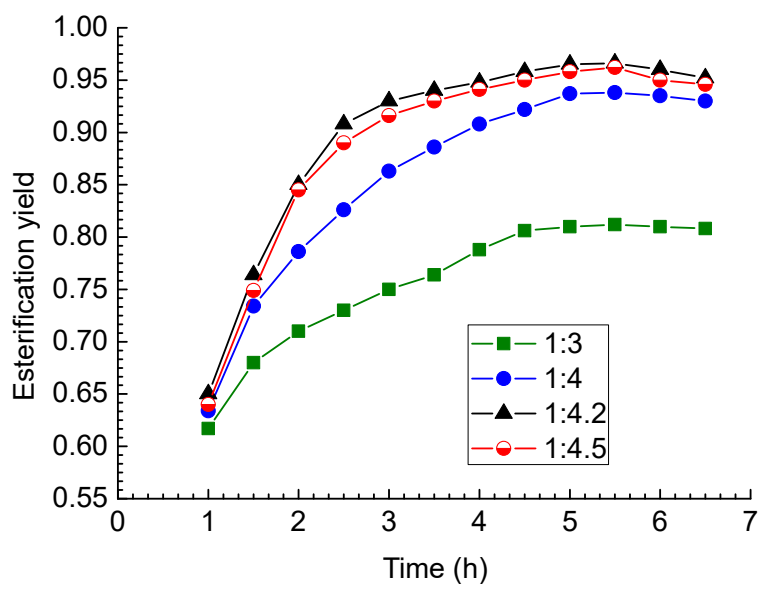

Fig. 4 Effect of the ratio of acid to alcohol on esterification yield.

increase when the temperature was above $150^{\circ} \mathrm{C}$, though the yield was almost unchanged. Considering the energy consumption problem, $150^{\circ} \mathrm{C}$ was chosen as the optimum reaction temperature.

\section{Effect of the ratio of acid to alcohol}

When the rotational speed was $450 \mathrm{r} / \mathrm{min}$, the particle size of ATP/AC catalyst was $180 \mu \mathrm{m}$, the reaction temperature was $150^{\circ} \mathrm{C}$, and the added amount of catalyst was $8 \%$, the effect of the ratio of acid to alcohol on the esterification yield under different reaction times was investigated. The results showed in Fig. 4 indicated that as the amount of n-butanol increased, the reaction yield also increased. This is because the reaction is a reversible reaction. The increase in amount of n-butanol is beneficial to the 


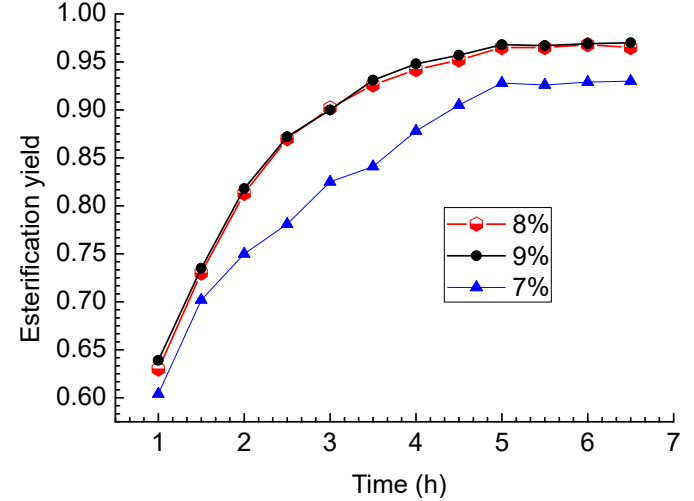

Fig. 5 Effect of the added amount of catalyst on esterification yield.

acceleration of the generation of the product. However, when the ratio of acid to alcohol was 1:4.5, the yield was slightly decreased. Therefore, it is not conducive to the synthesis of tributyl citrate with continuously increasing the amount of n-butanol. The optimum ratio of acid to alcohol was chosen to be $1: 4.2$.

\section{Effect of added amount of catalyst}

When the rotational speed was $450 \mathrm{r} / \mathrm{min}$, the particle size of ATP-AC catalyst was $180 \mu \mathrm{m}$, the reaction temperature was $150^{\circ} \mathrm{C}$, and the ratio of acid to alcohol was 1:4.2, the effect of added amount of ATP/AC catalyst on the esterification yield under different reaction times was investigated. The results shown in Fig. 5 indicated that the maximum yield of tributyl citrate was $92.6 \%$ when the added amount of catalyst was $7 \%$ of total reactant mass. The amount of catalyst was continuously increased. When the added amount of catalyst was $8 \%$ of the total reactant mass, the yield was the highest. When the amount of catalyst was continuously increased, the yield was no longer increased, and the optimum amount of catalyst was $8 \%$. The yield of tributyl citrate catalyzed by ATP-AC was higher than that of $\mathrm{H}_{4} \mathrm{SiW}_{12} \mathrm{O}_{40} / \mathrm{SiO}_{2}$ [18] and close to that of both modified silica gel supported phosphotungstic acid [19] and lanthum tri(dodecanesulfonate) [20].

\section{Reaction mechanism and kinetic equation}

\section{Esterification reaction mechanism of n-butanol and citric acid}

Fig. 6 shows the chromatogram of esterification reaction of citric acid and n-butanol catalyzed by ATP/AC, sampled under different times and mea- sured by gas chromatography-mass spectrometry. By the analysis, it was found that the retention times of citric acid, monobutyl citrate, dibutyl citrate, and tributyl citrate were $2.568,10.216,15.239$, and 15.585, respectively. As shown in Fig. 6, it can be observed that no by-products were produced throughout the catalytic esterification reaction. The reaction between citric acid and n-butanol was a multi-step reaction system, and the reaction mechanism was complex. The monobutyl citrate was first produced by the citric acid esterification. The steps of the esterification of citrate to produce both monobutyl citrate and dibutyl citrate were very fast. However, the rate of the formation of tributyl citrate by dibutyl citrate was relatively slow. This is similar to the results reported in literature $[18,21]$. Therefore, it is considered that the control step of this reaction is the production of tributyl citrate by the reaction of dibutyl citrate and n-butanol.

\section{Kinetic analysis}

According to the above-mentioned speculation, it can be considered that the reaction mechanism of dibutyl citrate and n-butanol catalyzed by AT$\mathrm{P} / \mathrm{AC}$ is as follows: the adsorption occurs between the reactants and solid catalyst under the catalysis of solid acid catalyst of aluminum didrogen tripolyphosphate; the reaction then occurs and the target product is finally produced. The solid acid is represented by $\mathrm{P}-\mathrm{M}$. Owing to the P-strong electrophilic effect and the weak acidity of dibutyl citrate, the reaction mechanism of dibutyl citrate and n-butanol catalyzed by solid acid catalyst can be assumed as follows, where $K_{i}, K_{i}^{\prime}, i=1,2,3, \ldots$ are the reaction rate constants for the forward reaction and the reverse reaction for each reaction, respectively.

First, adsorption dehydrogenation reaction of dibutyl citrate on acid sites of catalyst surface.

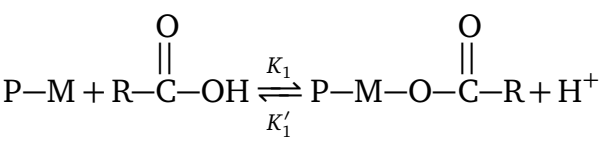

where $\mathrm{R}-\mathrm{COOH}$ is assumed to be $\mathrm{A}$ and $\mathrm{P}-\mathrm{M}-\mathrm{O}-\mathrm{CO}-\mathrm{R}$ is assumed to be $\mathrm{D}$.

Second, the formation of $\mathrm{R}_{1}-\mathrm{C}-\mathrm{H}$ by the bimolecular nucleophilic substitution reaction of $\mathrm{H}^{+}$ and n-butanol.

$$
\mathrm{H}^{+}+\mathrm{R}_{1}-\mathrm{OH} \underset{K_{2}^{\prime}}{\stackrel{K_{2}}{\rightleftharpoons}} \mathrm{R}_{1} \stackrel{\stackrel{\mathrm{I}}{\mathrm{O}}-\mathrm{H}^{+}}{ }
$$




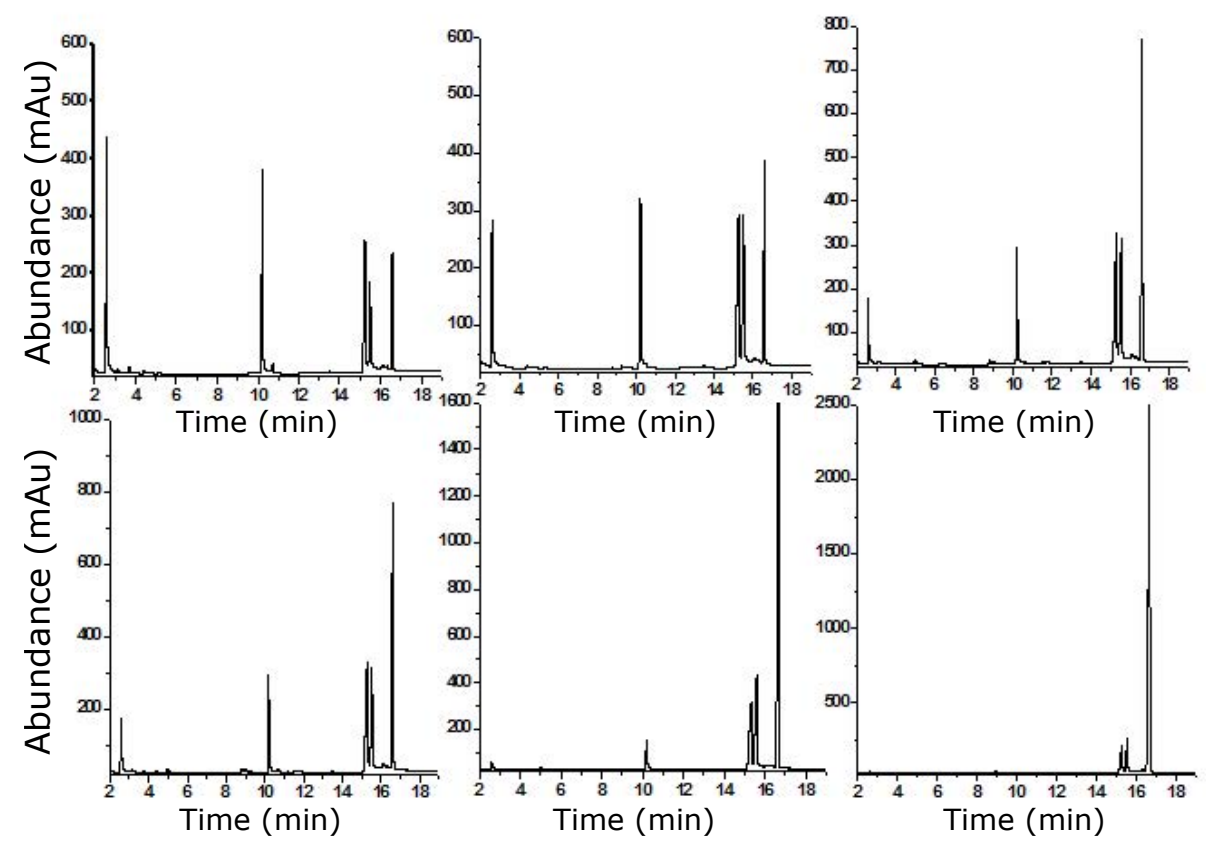

Fig. 6 Gas chromatogram of products under different reaction times.

where $\mathrm{R}_{1}-\mathrm{O}-\mathrm{H}$ is assumed to be $\mathrm{B}, \mathrm{H}^{+}$is $\mathrm{E}$, and $\mathrm{R}_{1}-\mathrm{OH}-\mathrm{H}^{+}$is $\mathrm{C}$.

Third, desorption of hydroxyl groups in the adsorbed state on the catalyst.

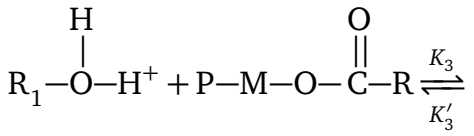

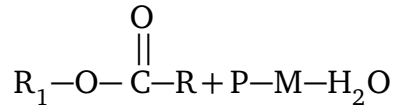

where $\mathrm{R}_{1}-\mathrm{O}-\mathrm{CO}-\mathrm{R}$ is assumed to be $\mathrm{F}$ and $\mathrm{P}-\mathrm{M}-\mathrm{H}_{2} \mathrm{O}$ is $\mathrm{G}$.

\section{Reaction kinetics}

In the experiment, the influences of both internal and external diffusions were eliminated by controlling the particle size of catalyst and the stirring speed. The synthesis of tributyl citrate by citric acid and n-butanol using ATP/AC as a catalyst is a series of reactions. The first and second steps of the reaction are fast while the third step is slow, which is the control step. Furthermore, it is assumed that the desorption reaction process of adsorbing carboxyl groups on the catalyst is the control step, and the rate equation is as follows:

$$
r=K_{3} C_{C} \theta_{D}-K_{3}^{\prime} C_{F} C_{G}\left(1-\theta_{D}\right)
$$

$$
r=r_{3}=r_{F}=K_{3} C_{C} \theta_{D}-K_{3}^{\prime} C_{F} C_{G}\left(1-\theta_{D}\right) \text {. }
$$

Because of the adsorption in (1) and (2), the nucleophilic substitution reaction quickly reaches equilibrium, so there are:

$$
r_{1}=K_{1} C_{A}\left(1-\theta_{D}\right)-K_{1}^{\prime} C_{E} \theta_{D}=0,
$$

where $\theta_{D}$ is adsorption coverage rate, and

$$
r_{2}=K_{2} C_{B} C_{E}-K_{2}^{\prime} C_{C}=0 .
$$

From (3), the following can be obtained:

$$
C_{E}=\frac{K_{1} C_{A}\left(1-\theta_{D}\right)}{K_{1}^{\prime} \theta_{D}} .
$$

From (4) and (5), the following can be obtained:

$$
C_{C}=\frac{K_{2} C_{B} C_{E}}{K_{2}^{\prime}}=\frac{K_{1} K_{2}\left(1-\theta_{D}\right) C_{A} C_{B}}{K_{1}^{\prime} K_{2}^{\prime} \theta_{D}} .
$$

From (2) and (6) we get

$$
\begin{aligned}
r=r_{3}=r_{F} & =\frac{K_{1} K_{2} K_{3}\left(1-\theta_{D}\right) C_{A} C_{B}}{K_{1}^{\prime} K_{2}^{\prime}}-K_{3}^{\prime} C_{F} C_{G}\left(1-\theta_{D}\right) \\
& =K_{4} L\left[C_{A} C_{B}-\frac{C_{F} C_{G}}{K}\right],
\end{aligned}
$$

where $L=1-\theta_{D}$ can be regarded as a constant, $K_{4}=\frac{K_{1} K_{2} K_{3}}{K_{1}^{\prime} K_{2}^{\prime}}$ and $K=\frac{K_{1} K_{2} K_{3}}{K_{1}^{\prime} K_{2}^{\prime} K_{3}^{\prime}}$. By setting $k=K_{4} L$, we obtain

$$
r=r_{F}=k\left[C_{A} C_{B}-\frac{C_{R} C_{G}}{K}\right] .
$$




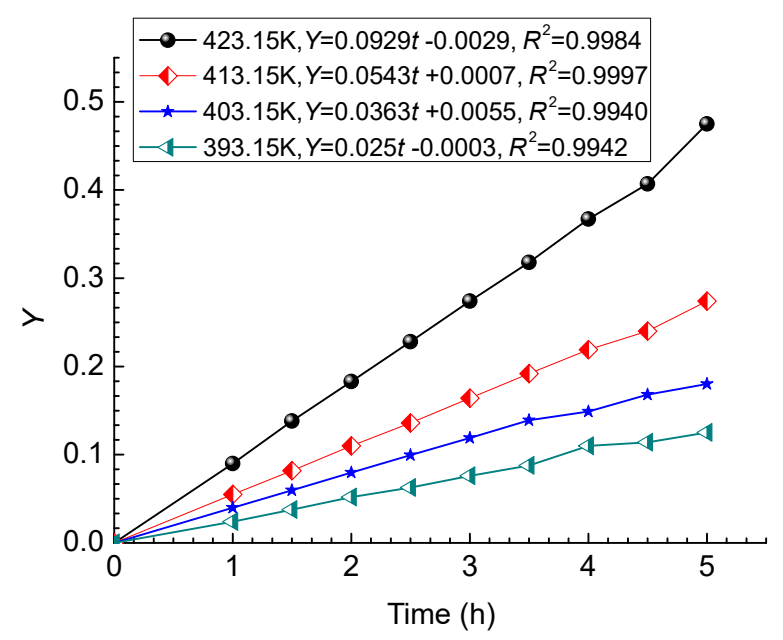

Fig. 7 Relationship between $Y$ and $t$.

The products of $\mathrm{F}$ and $\mathrm{G}$ can be obtained by total stoichiometric formulas of the reaction of $\mathrm{A}$ and $\mathrm{B}$, which can be obtained as follows:

$$
r=r_{F}=k C_{\mathrm{A} 0}\left[C_{\mathrm{A} 0}(1-x)(n-x)-\frac{C_{\mathrm{A} 0} x^{2}}{K}\right],
$$

where $k=K_{4} L$ is the positive reaction rate constant, $K=\frac{K_{1} K_{2} K_{3}}{K_{1}^{\prime} K_{2}^{\prime} K_{3}^{\prime}}$ is the chemical equilibrium constant, $C_{\mathrm{A} 0}$ is the initial concentration of citric acid and $x$ is the conversion rate of citric acid.

The following equation can be obtained from the molar concentration of each component after the reaction equilibrium: $r_{F}=\frac{\mathrm{d} C_{F}}{\mathrm{~d} t}=C_{\mathrm{A} 0} \frac{\mathrm{d} x}{\mathrm{~d} t}$.

Substituting into (9):

$$
\frac{\mathrm{d} x}{\mathrm{~d} t}=k C_{\mathrm{A} 0}\left[(1-x)(n-x)-\frac{x^{2}}{K}\right] .
$$

The following can be obtained by the integral from the formula above: $k t=Y$, where $k=$ $k_{0} \mathrm{e}^{\left(-E_{a} / R T\right)}, k_{0}$ is the pre-exponential factor. It is commanded as follows:

$$
Y=\int_{0}^{x} \frac{1}{C_{\mathrm{A} 0}\left[(1-x)(n-x)-\frac{x^{2}}{K}\right]} \mathrm{d} x .
$$

The plotting is made by taking $Y$ as the ordinate and $t$ as the abscissa, and the slope $k$ of a straight line is obtained. The linear relationship is shown between $Y$ and $t$.

The reaction conditions were optimized. Those were $180 \mu \mathrm{m}$ of particle size, $550 \mathrm{r} / \mathrm{min}$ of stirring speed, 1:4.2 of the ratio of acid to alcohol, $8 \%$ of catalyst accounting for total reaction amount, $5 \mathrm{~h}$ of

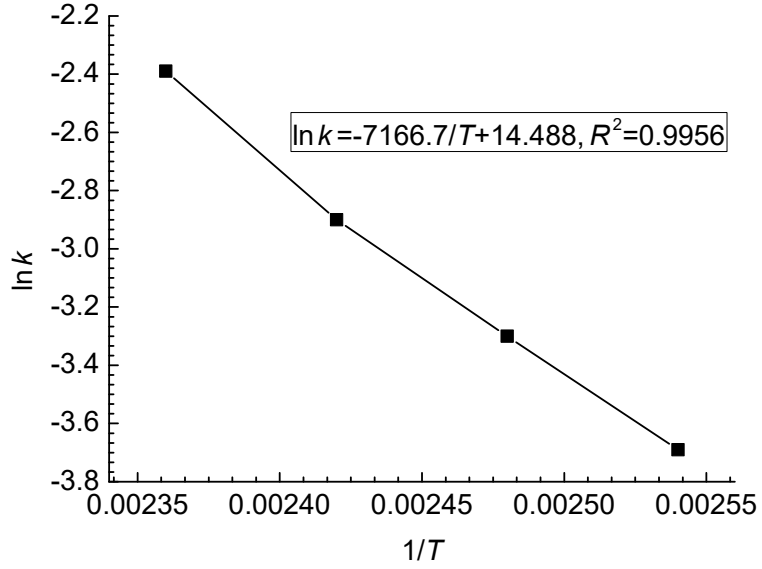

Fig. 8 Relationship between $\ln k$ and $1 / T$.

reaction time for water segregating and refluxing, and $150^{\circ} \mathrm{C}$ of reaction temperature. Fig. 7 was obtained by the plotting and taking $Y$ as the ordinate and $t$ as the abscissa. It was found that the linear correlation coefficient of $R^{2}$ for each straight line was between 0.989 and 0.993 , indicating that the linear relationship was shown in $Y$ and $t$ with the slope of $k$. Then, as shown in Fig. 8, the plotting was made by taking $\ln k$ with $1 / T$. From Fig. 8 , it can be seen that the linear relationship was shown between $\ln k$ and $1 / T$. The linear correlation coefficient was $R^{2}=0.9956$. The frequency factor of $k_{0}$ and the apparent activation energy of $E_{a}$ were obtained: $E_{a}=61.4 \mathrm{~kJ} / \mathrm{mol}, k_{0}=1.33 \times 10^{5}$, and $\ln k=$ $-61.4 / R T+11.8$. The reaction kinetic equation was $\frac{\mathrm{d} x}{\mathrm{~d} t}=1.33 \times 10^{5} \times \mathrm{e}^{\frac{-61.4}{R T}} C_{\mathrm{A} 0}\left[(1-x)(n-x)-\frac{x^{2}}{K}\right]$.

\section{Verification of kinetic equation}

Table S1-Table S4 were the comparison results of actual yield and theoretical yield of tributyl citrate synthesized by the catalysis of ATP/AC at different reaction temperatures of $150^{\circ} \mathrm{C}, 140^{\circ} \mathrm{C}, 130^{\circ} \mathrm{C}$, and $120^{\circ} \mathrm{C}$, respectively. As shown in Table S1-Table S4, it can be observed that the average errors of relative errors of actual and theoretical values of the yields at different temperatures within different times were less than $2.5 \%$. This indicated that the experimental results were close to the predicted values. The model could be used to predict the experimental results. Therefore, it can be explained that the obtained kinetic model is valid.

\section{Characterization of the product}

The TBC obtained by the catalysis over ATP/AC is an oily liquid with a light yellow color. Its infrared 


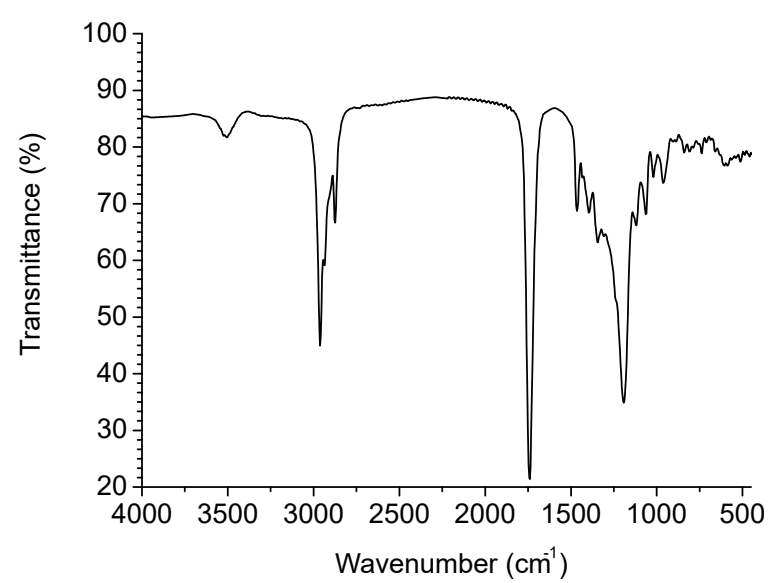

Fig. 9 FT-IR of the product.

spectrum is shown in Fig. 9. It can be seen that it is the stretching vibration absorption peak of $-\mathrm{OH}$ at $3503 \mathrm{~cm}^{-1}$. At $2962 \mathrm{~cm}^{-1}$, it is the $\mathrm{C}-\mathrm{H}$ absorption peak on methyl groups. It is a characteristic absorption peak at $1741 \mathrm{~cm}^{-1}$. It is the $\mathrm{C}-\mathrm{O}-\mathrm{C}$ absorption peak of ester at $1192 \mathrm{~cm}^{-1}$ and $1063 \mathrm{~cm}^{-1}$ [22]. The refractive index of the obtained TBC is tested to be $n_{D}^{20}=1.4457$, which is consistent with literature value $\left(n_{D}^{20}=1.4459\right)$ [23].

\section{CONCLUSION}

In this work, synthetic kinetics of tributyl citrate using alumimun dihydrogen tripolyphosphate supported on modified activated carbon as a catalyst has been successfully demonstrated. when the particle size was smaller than $180 \mu \mathrm{m}$ and the rotational speed was higher than $450 \mathrm{r} / \mathrm{min}$, the internal and external diffusions could be eliminated. The yield of tributyl citrate reached $97 \%$ under the following optimized conditions: $1: 4.2$ of ratio of acid to alcohol, $8 \%$ of catalyst accounting for total reaction amount, $5 \mathrm{~h}$ of reaction time for water segregating and refluxing, and $150{ }^{\circ} \mathrm{C}$ of reaction temperature. The reaction mechanism of citric acid and n-butanol catalyzed by ATP/AC was that the monobutyl citrate was first formed and the rate of dibutyl citrate was very fast. The control step was the reaction of between dibutyl citrate and n-butanol to form tributyl citrate. The apparent activation energy was $E_{a}=$ $61.4 \mathrm{~kJ} / \mathrm{mol}$. Through experimental verification, the relative average errors of actual value and the theoretical value of the yields at different times were less than $2.5 \%$, and the obtained kinetic model was valid.

\section{Appendix A. Supplementary data}

Supplementary data associated with this article can be found at http://dx.doi.org/10.2306/ scienceasia1513-1874.2021.022.

Acknowledgements: This work was supported by the National Nature Science Foundation of China (No. 21666006).

\section{REFERENCES}

1. Nandiwale KY, Gogoi P, Bokade VV (2015) Catalytic upgrading of citric acid to environmental friendly tributyl citrate plasticizer over ultra stable phosphonated Y zeolite. Chem Eng Res Des 98, 212-219.

2. Li G, Cao F, Wang DT (2015) Catalytic synthesis of green plasticizer tributyl citrate. Chem World 56, 110-114.

3. Jeon Y, Chi WS, Hwang J, Kim DH, Kim JH, Shul Y (2019) Core-shell nanostructured heteropoly acidfunctionalized metal-organic frameworks: Bifunctional heterogeneous catalyst for efficient biodiesel production. Appl Catal B Environ 242, 52-59.

4. Yu FL, Wang QY, Yuan B, Xie CX, Yu ST (2017) Alkylation desulfurization of FCC gasoline over organicinorganic heteropoly acid catalyst. Chem Eng $J$ 309, 298-304.

5. Nandiwale KY, Borikar SP, Bokade VV (2015) Synthesis of non-toxic triethyl citrate plasticizer by esterification of renewable citric acid using modified zeolite. Clean (Weinh) 43, 927-931.

6. Rishi SK, Kariuki MB, Checker JN, Godber J, Wright JA (2006) Synthesis and crystal structure of $\mathrm{AlH}_{2} \mathrm{P}_{3} \mathrm{O}_{10} \cdot 2 \mathrm{H}_{2} \mathrm{O}$; a new structure-type for layered acid phosphates. Chem Commun 37, 747-749.

7. Wu SF, Huang RJ, Chen DL, Huang ZW, Ma SM, Yuan AQ (2014) Characteristics of intercalation reaction between aluminum dihydrogen tripolyphosphate and organic amine. Chin J Appl Chem 31, 847-851.

8. Matskevich NI, Wright A, Wolf T, Vyazovkin IV, Anyfrieva OI, Matskevich MY (2017) Aluminum dihydrogen tripolyphosphate: thermodynamic characteristics. $J$ Chem Thermodyn 111, 27-30.

9. Hayashi A, Saimen H, Watanabe N, Watanabe N, Kimura H, Kobayashi A, Nakayama H, Tsuhako M (2005) Intercalation of gaseous thiols and sulfides into $\mathrm{Ag}+$ ion-exchanged aluminum dihydrogen triphosphate. Langmuir 21, 7238-7242.

10. Huang ZW, Yuan AQ, Shi ZW, Huang QL, Deng GH, Tong ZF (2008) Spectroscopy characteristics of various aluminum phosphates in $\mathrm{Al}_{2} \mathrm{O}_{3}-\mathrm{P}_{2} \mathrm{O}_{5}-\mathrm{H}_{2} \mathrm{O}$ system and its high temperature products. Spectrosc Spect Anal 28, 638-641.

11. Nishikawa H, Oiso Y, Ishihara M (2007) Photocatalytic behavior of layered aluminum dihydrogen 
triphosphate under UV irradiation. Mater Lett 61, 1820-1822.

12. Huang RJ, Xie W, Wang J, Chen DL, Huang ZW, Wei DP, Ma SM, Yuan AQ (2015) Synthesis of tributyl citrate catalyzed by aluminum dihydrogen tripolyphosphate/loaded sulfur diatomite. China Plastics Ind 43, 105-108.

13. Huang RJ, Wang J, Xie W, Chen DL, Huang ZW, Wei DP, Ma SM, Yuan AQ (2015) Synthesis of benzaldehyde glycol acetal catalyzed by aluminum dihydrogen tripolyphosphate/loaded sulfur diatomite. Fine Chem 32, 422-425.

14. Gokce Y, Aktas Z (2014) Nitric acid modification of activated carbon produced from waste tea and adsorption of methylene blue and phenol. Appl Surf Sci 313, 352-359.

15. Macías-García A, Díaz-Díez MA, Cuerda-Correa EM, Olivares-Marín M, Gañan-Gómez J (2006) Study of the pore size distribution and fractal dimension of $\mathrm{HNO}_{3}$-treated activated carbons. Appl Surf Sci 252, 5972-5975.

16. Huang RJ, Chen DL, Huang ZW, Wei DP, Liang H, Yuan AQ (2017) Synthesis of tributyl citrate catalyzed by aluminum dihydrogen tripolyphosphate loaded activated carbon modified by $\mathrm{Na}_{2} \mathrm{~S}_{2} \mathrm{O}_{8}$. Appl Chem Ind 46, 225-229.
17. Khudsange RC, Wasewa LK (2018) Kinetics, mass transfer, and thermodynamic and statistical modeling study for esterification of valeric acid with nbutanol: homogeneous and heterogeneous catalysis. Int $J$ Chem Kinet 50, 710-725.

18. Zhou HF, LI WZ, Zhang LQ (2014) Catalytic synthesis of tri-butyl citrate with $\mathrm{H}_{4} \mathrm{SiW}_{12} \mathrm{O}_{40} / \mathrm{SiO}_{2}$. Chem Res Appl 26, 125-129.

19. Nie LJ, Wang K, Li XM, Tian SJ (2012) Catalytic synthesis of tri-butyl citrate by modified silica gel supported phosphotungstic acid. Chem Res Appl 24, 1795-1799.

20. Du XH (2017) Synthesis of tri-n-butyl citrate using lanthum tri(dodecanesulfonate) as catalyst. Chem World 58, 395-399.

21. Zheng Y, Yue J-c, Wang J-y, Tan M-c, Zheng S-q (2004) Kinetic study on synthesis of tributyl citrate catalyzed by tetrabutyl titanate. J Qingdao Univ Sci Tech 25, 197-201.

22. Wang LM, Ding B, Zhang M (2019) Preparation supported heteropoly (acid)/polyaniline catalysts and catalytic synthesis of tributyl citrate. RSC Adv 57, 33124-33129.

23. Long JQ, Cheng HN, Li YC, Jiang S (2012) Catalytic synthesis of tributyl citrate by green plasticizer. Bull Sci Technol 28, 126-129. 


\section{Appendix A. Supplementary data}

Table S1 Error analysis at different reaction times at $150^{\circ} \mathrm{C}$.

\begin{tabular}{lccrr}
\hline Reaction time $(\mathrm{h})$ & Theoretical yield & Actual yield & Error & Average error \\
\hline 5 & $97.25 \%$ & $97.00 \%$ & $-0.26 \%$ & $1.51 \%(<2.5 \%)$ \\
4 & $92.90 \%$ & $94.80 \%$ & $2.00 \%$ & \\
3 & $88.60 \%$ & $90.80 \%$ & $2.40 \%$ & \\
2 & $80.90 \%$ & $81.40 \%$ & $0.60 \%$ & \\
1.5 & $74.60 \%$ & $73.00 \%$ & $-2.10 \%$ & \\
1 & $66.80 \%$ & $68.00 \%$ & $1.70 \%$ & \\
\hline
\end{tabular}

Table S2 Error analysis at different reaction times at $140^{\circ} \mathrm{C}$.

\begin{tabular}{lccrr}
\hline Reaction time $(\mathrm{h})$ & Theoretical yield & Actual yield & Error & Average error \\
\hline 5 & $88.70 \%$ & $90.70 \%$ & $2.20 \%$ & $1.8 \%(<2.5 \%)$ \\
4 & $85.90 \%$ & $86.40 \%$ & $0.57 \%$ & \\
3 & $77.20 \%$ & $78.50 \%$ & $1.66 \%$ & \\
2 & $69.60 \%$ & $68.00 \%$ & $-2.30 \%$ & \\
1.5 & $60.20 \%$ & $59.00 \%$ & $2.00 \%$ & \\
1 & $52.70 \%$ & $51.60 \%$ & $-2.15 \%$ & \\
\hline
\end{tabular}

Table S3 Error analysis at different reaction times at $130^{\circ} \mathrm{C}$.

\begin{tabular}{lcccc}
\hline Reaction time $(\mathrm{h})$ & Theoretical yield & Actual yield & Error & Average error \\
\hline 5 & $80.20 \%$ & $82.00 \%$ & $2.10 \%$ & $1.91 \%(<2.5 \%)$ \\
4 & $75.40 \%$ & $76.00 \%$ & $0.79 \%$ & \\
3 & $66.20 \%$ & $64.50 \%$ & $-2.60 \%$ & \\
2 & $54.00 \%$ & $53.00 \%$ & $-1.80 \%$ & \\
1.5 & $51.50 \%$ & $49.80 \%$ & $-3.40 \%$ & \\
1 & $44.60 \%$ & $45.00 \%$ & $0.85 \%$ & \\
\hline
\end{tabular}

Table S4 Error analysis at different reaction times at $120^{\circ} \mathrm{C}$.

\begin{tabular}{lcccc}
\hline Reaction time $(\mathrm{h})$ & Theoretical yield & Actual yield & Error & Average error \\
\hline 5 & $69.30 \%$ & $70.50 \%$ & $1.70 \%$ & $1.69 \%(<2.5 \%)$ \\
4 & $64.00 \%$ & $63.50 \%$ & $0.79 \%$ & \\
3 & $51.80 \%$ & $53.00 \%$ & $2.20 \%$ & \\
2 & $43.10 \%$ & $44.00 \%$ & $1.10 \%$ & \\
1.5 & $42.00 \%$ & $41.00 \%$ & $-2.40 \%$ & \\
1 & $40.30 \%$ & $39.50 \%$ & $-2.00 \%$ & \\
\hline
\end{tabular}

